\title{
Computer-based selection testing in the Royal Air Force
}

\author{
DAVID R. HUNTER \\ U.S. Army Research Institute, St. Louis, Missouri \\ and \\ EUGENE F. BURKE \\ Science 3 (Air), Ministry of Defence, London, England
}

\begin{abstract}
This paper describes efforts conducted to implement computer-based selection testing for officers (pilots and aircraft controllers) in the Royal Air Force. The history leading to the decision to computerize the selection testing is recounted, along with the procedures used to develop computerbased tests equivalent to the existing electromechanical-based tests. The development and validation of a battery of computer-based tests for the selection of RAF aircraft controllers is also described. The present status of computer-based selection testing in the RAF is discussed, along with future directions of inquiry.
\end{abstract}

The use of apparatus tests for the selection of Royal Air Force (RAF) personnel dates from the late 1930s and the development of the Reid Machine, which measured the speed of movement of aircraft-like controls (Bartlett \& Craik, 1939). At about the same time, the United States Army Air Force began to experiment with a device that became known as the Complex Coordinator, developed by Mashburn (1934a, 1934b). Each of these devices used the electromechanical technology of the time to assess psychomotor coordination for the prediction of flight training performance, and both were used throughout the war for the selection of pilots for the two services.

In the years following World War II, the United States Air Force discontinued the use of apparatus tests for aircrew selection, principally because the electromechanical devices could not be kept in service and properly calibrated while being shipped around the country to the various testing sites. In the United Kingdom, however, the Officer and Aircrew Selection Centre (OASC) was established at RAF Biggin Hill. All current assessments for the roles of pilot, navigator, air-traffic and fighter controllers, and noncommissioned officer aircrew remain at this centralized testing site, thereby facilitating the continued use of apparatus-based tests.

Despite modernization of the electromechanical machines used in testing psychomotor and perceptual abilities, the cost of maintenance and replacement parts led to consideration of alternative media through which such

This work was performed while the principal author was employed by the U.S. Air Force Human Resources Laboratory, and on assignment to the Ministry of Defence. The second author is currently on reciprocal assignment at Brooks Air Force Base, San Antonio, TX.

The views expressed herein are those of the authors and do not necessarily reflect the official views or policies of the United States Army or the United Kingdom Ministry of Defence. Send reprint requests to: David R. Hunter, Army Research Institute, ATTN: PERI-IRA, 4300 Goodfellow Blvd., St. Louis, MO 63120-1798. testing could be accomplished. The solution adopted was to transfer existing tests to microcomputers, given the likely increases in both the flexibility and reliability in test administration that would be achieved. This decision was, however, contingent upon the demonstration that equivalent forms of the two apparatus tests used for pilot selection could be developed on the computer. Those two tests were the Sensory Motor Apparatus (SMA) and the Control of Velocity Test (CVT).

\section{COMPUTERIZATION OF SMA AND CVT}

The SMA is a direct descendant of the Reid Machine of World War II, and a close cousin to the American version, the Complex Coordinator. The current version uses aircraft-like controls (stick and rudder) to control the movement of a cursor displayed on a cathode ray tube (CRT). The object of the test is to keep the cursor from drifting outside a circle shown on the CRT. A simple timeon-target score is produced.

The CVT uses a rotating drum that passes under a pointer controlled by the examinee. The metal drum is covered with a plastic sheet on which holes have been cut at varying points along a spiral track. The object of the test is to move the pointer along the spiral track and hit as many of the holes as possible. The score is the number of hits obtained. As the name implies, this test uses a velocity-input control.

The development of new computerized versions of these existing tests was undertaken by Science 3 (Air), the United Kingdom Ministry of Defence psychological research establishment responsible for RAF selection test development. As the first step in this effort, computer analogs of both tests were developed on a PDP-11/34 computer system using the VR-17 color graphics system. The programming language was FORTRAN. The displays and 
control functions duplicated as closely as possible the apparatus tests. Following initial tryouts at Science 3, the software was transferred to a PDP-11/23-based system at the OASC. All incoming pilot candidates were thereafter tested on both the apparatus-based tests and the new computer-based tests, and their scores on the old and new versions of the tests were correlated. Based upon a sample of approximately 200 candidates, correlations between the old and new versions of the SMA and the old and new versions of the CVT were found to be .75 and .64 , respectively. These correlations approximated the reliabilities of the old tests, and supported the contention that computer-based tests could be developed that are equivalent to the old apparatus-based tests.

Following acceptance of the equivalence of the computer versions of the psychomotor tests, the process of transfer was extended to existing paper-and-pencil measures. The first of these to be transferred was the Instrument Comprehension Test, used in the selection of RAF pilots. This is a speeded test requiring the applicant to indicate which of five verbally described aircraft conditions reflects data given by standard cockpit instruments (e.g., altimeter, compass, etc.). This is a two-part test, and correlations between the paper-and-pencil and computer versions were again found to approximate the reliabilities of the paper-and-pencil version.

\section{PARALLEL EFFORTS FOR AIRCRAFT CONTROLLERS}

With the anticipated introduction of automated testing facilities, research was undertaken to utilize these facilities to extend personnel testing through dynamic measures. The development of these new tests was initiated for the roles of fighter and air-traffic controllers. Interest in the development of a test battery for the selection of individuals for training in these two areas developed because of an unacceptably high rate of attrition from training, coupled with a traditional concern in the United Kingdom over the quality of air defense. In addition, recent studies by Science-3 had shown that the existing paperand-pencil selection tests were of marginal validity.

An initial battery of 22 tests (listed in Table 1) was de- vised, representing many traditional measures along with some tests patterned after particular elements of the controllers' jobs. These tests were programmed onto a Research Machines Model 380Z microcomputer and administered from January 1983 until March 1984 to all incoming student controllers. Correlation of test scores with training outcomes showed that several of the tests were reliably correlated with success in training.

\section{CONVERSION TO CONPUTER-BASED SELECTION TESTING}

The results from these two parallel efforts demonstrated that: (1) the existing pilot selection tests could be migrated to a computer-based format while (probably) retaining their validities, and (2) the use of computer-based tests could significantly improve selection for other specialties. As a consequence, the RAF management elected to implement computer-based selection testing and to abandon the old electromechanical testing devices. Automated selection test batteries for the pilot and controller roles are presently being implemented on Torch computer systems (roughly equivalent to IBM PCs) at the OASC.

The advent of computer-based selection testing in the RAF is expected to improve the psychometric characteristics (reliability, validity) of the tests and provide significant new capabilities for the development and evaluation of new tests. The flexibility of computer-based testing will allow new tests to be developed, evaluated, and modified in a continuing cycle. On-line monitoring of examinee characteristics will allow the RAF to continuously check on the quality of its applicants. By linking the Science-3 computer, which is the repository for the RAF training outcome data, with the testing system, a continuous validation of the selection tests may be conducted, thus identifying early the need for new tests or changes to weights assigned to tests in a selection battery, should predictive validities change.

Further research in this area will be conducted to confirm the validities of the computer-based tests and to eventually convert all existing selection tests to a computer format. Plans are also under way to further investigate the dynamic characteristics of computer-based testing to

Table 1

Controller Aptitude Battery

\begin{tabular}{ll}
\hline (1) Annett Handedness Questionnaire & (12) Sternberg Test \\
(2) Keyboard Familiarity Test & (13) Visual Scanning Test I \\
(3) Angles, Bearings, and Headings Test & (14) Visual Scanning Test II \\
(4) Manikin Test & (15) Reaction Time I \\
(5) Search & (16) Reaction Time II \\
(6) AB Reasoning Test & (17) Reaction Time III \\
(7) Speed Estimation Test & (18) Dual-Task Performance \\
(8) Visual Comparisons Test & (19) Conflict Prediction \\
(9) Visual Memory Test & (20) Pattern Recognition \\
(10) Digit Span I & (21) Vigilance \\
(11) Digit Span II & (22) Maze Test \\
\hline
\end{tabular}


assess attributes not amenable to testing with paper and pencil.

The advantages inherent in computer-based testing represent a major step forward in the selection testing for the RAF. It is a step that resulted from the close cooperation of Science-3 researchers and RAF staffs. Together, they were able to bring together management, scientific, and operational viewpoints to produce a system whose benefits will no doubt become ever more evident as it matures.

\section{REFERENCES}

Bartlett, F. C., \& Craik, K. J. (1939). Report on the Reid Machine (Report No. 59). London, England: Flying Personnel Research Committee, Royal Air Force, Ministry of Defence.

MASHBURN, N. C. (1934a). The complex coordinator as a performance test in the selection of military flying personnel. Journal of Aviation Medicine, 5, 145-154.

MashbuRN, N. C. (1934b). Mashburn automatic serial action apparatus for detecting flying aptitude. Journal of Aviation Medicine, $\mathbf{5}$, 155-160. 